\title{
Parents' Descriptions of How Their Psychosis Affects Parenting
}

\author{
Jennifer Strand ${ }^{1} \cdot$ Petra Boström ${ }^{1} \cdot$ Karin Grip ${ }^{1}$
}

Published online: 10 October 2019

(c) The Author(s) 2019

\begin{abstract}
Objectives Parental psychosis poses a risk factor for a child's well-being. Few studies have focused on the parents' views of how their psychosis affects their parenting, and results for parenting ability in this group are contradictory. The present study aimed to explore how parents with psychosis experience the effect(s) of their illness on parenting.

Methods In-depth and semi-structured interviews were conducted with 15 parents who attended outpatient clinics specializing in psychosis. The transcripts were analyzed using thematic analysis. Data related to the research aim were analyzed deductively according to the protection, reciprocity, control, guided learning, and group participation model of parenting. Data in each domain were subsequently coded inductively to form subthemes.

Results Results show that all domains of parenting appear to be affected by psychosis. The parents specifically mentioned that depression, fatigue, and difficulty focusing because of hearing voices had negative impacts on their abilities to provide protection, reciprocity, and control. The parents also expressed difficulties in maintaining routines in the child's everyday life. Furthermore, the theme "Unpredictable absences" crosses all domains and highlights the parents' recurrent mental and physical absences from their children during psychotic episodes.

Conclusions The present study provides some insight into how different aspects of parenting may be affected by psychosis. We suggest that these effects on parenting need to be further explored and confirmed by research focusing on the child's perspective and on observations of parent-child interaction.
\end{abstract}

Keywords Parental psychosis $\cdot$ Parenting $\cdot$ Psychiatric services $\cdot$ Schizophrenia $\cdot$ Qualitative study

Nearly $6 \%$ of children in Sweden grow up with a parent with mental illness (Hjern and Manhica 2013), but international figures point to as many as one in five children (Reupert et al. 2012). International as well as studies from Scandinavia estimate that a substantial minority of patients in adult psychiatric care have children under 18 years old (Lauritzen 2014; Maybery and Reupert 2018; Ruud et al. 2019). The increased risk of developing mental health problems is well established in children growing up with a parent with mental illness (LeFrancois 2012; Leijdesdorff et al. 2017; Ramchandani and Psychogiou 2009).

Supplementary information The online version of this article (https:// doi.org/10.1007/s10826-019-01605-3) contains supplementary material, which is available to authorized users.

Jennifer Strand

jennifer.strand@psy.gu.se

1 Department of Psychology, University of Gothenburg, Box 500, 405 30, Gothenburg, Sweden
Parenting can be both greatly rewarding and a daunting task for anyone, but the complex task of parenting is more challenging when the parent with severe mental illness (Campbell et al. 2012; Wan and Green 2009). Fathers and mothers with severe mental illness experience all of the challenges of other adults struggling to balance their roles as workers, spouses, and parents. The symptoms of mental illness, however, may cause disturbances in thought and behaviors that result in difficulties handling the parenting role (Blegen et al. 2010, 2012; Krumm et al. 2013). The relationship between mental illness in parents and its impact on parenting and child outcomes is complex and remains to be fully elucidated. First, there can be a direct causal relationship based on genetic inheritance of liability from parents to offspring (Ripke et al. 2014), the effect of maternal mental illness in pregnancy through fetal programming (Stein et al. 2014), and the effect of maternal and paternal severe mental illness on parenting behavior, the parent-child relationship, and general family functioning (Smith 2004). 
Studies have reported impaired parenting capacity in parents with psychosis (Diaz-Caneja and Johnson 2004; Engur 2017, Evenson et al. 2008). Many studies of mothers with psychosis reveal that they struggled with problems in everyday parenting, including ensuring and asserting discipline and maintaining boundaries, problems in their parental role due to symptoms of the illness or side effects of medication, and feelings of guilt, shame, and fear of the possible effects of their illness on their children (Dolman et al. 2013). However, a large study of parents with psychosis $(n=234)$ reports that most had good-enough or adequate parenting defined as participation, interest, and competence in childcare over the last 12 months as rated by trained clinicians (Campbell et al. 2018).

Parenting is multiply determined and influenced by characteristics of the parent, the child, and the family's social context (Belsky 1984). Recent research on parenting has attempted to develop domain-specific models to investigate discrete dimensions of parenting (Grusec and Davidov 2010). A domain-specific model recognize that caregiving is multi-dimensional and involves a variety of specific practices or actions in a variety of specific contexts. The need of investigating specific parenting practices used in specific contexts or domains of child activities, behaviours, or needs has been put forward by socialization researchers (Bornstein et al. 2008; Grusec and Davidov 2010; Turiel 2010). General and global characterizations of parenting can fail to recognize that parenting practices may be adequate and positive in one context but inadequate or harmful in another. Grusec and Davidov (2010) used a behavioral systems approach and described parenting in the context of the different needs and childrearing goals that are activated in different situations. Parenting is depicted as using different practices flexibly depending on their childrearing goals, their children's needs, and the types of child behaviors toward which their parenting is directed. The model proposes five main domains of socialization: protection; reciprocity; control; guided learning; and group participation. The different domains require different parenting competences and skills and encourage children to acquire different social, cognitive, and emotional competences. (Each domain is briefly described in the Results section).

Currently, it seems clear that parental psychosis poses a risk to the child's well-being. Despite this risk, few studies focus on the parents' own views of how their psychosis affects their parenting, and results regarding parenting ability in this group are somewhat contradictory. The present study aimed to explore how parents with psychosis experience the effect(s) of their illness on parenting. The parents' subjective understandings were analyzed in terms of the domains of parenting (protection, reciprocity, control, guided learning, and group participation) suggested in Grusec and Davidov's (2010) model of parenting.

\section{Method}

\section{Participants}

The study included 15 parents (10 mothers and 5 fathers) with an average age of 42 years (range 36-56, $\mathrm{SD}=5.70$ ). Two of the parents worked half-time or more, one was on parental leave, and the other 12 were on sick leave. All but two of the parents had 12 or more years of education. One participant had been in contact with psychiatric services for two years, three participants for five to six years, four for eight to ten years, and six for more than ten years. The participants' primary diagnoses were schizoaffective disorder (8), schizophrenia (2), psychotic disorder (3) and major depressive disorder with psychotic episodes (2).

Eight parents were married or co-habiting and seven were divorced and lived as single parents. Ten parents lived with their children, three had alternating living arrangements with the other parent, and two had a right of access to their children, i.e., no legal custody but regulated allowance to see their child. The 15 parents had 17 children ( 11 boys and 6 girls) between 3 and 16 years of age, with an average age of 10 years $(\mathrm{SD}=4.09)$.

\section{Procedure}

The data comes from a project examining the implementation of two child-focused interventions for parents with mental illness: Let's Talk About Children (Solantaus and Toikka 2006) and Beardslee's family intervention (Beardslee et al. 2003). The parents were recruited from outpatient clinics specializing in psychosis in 2015-2017 in the second largest city in Sweden.

Eight open-care psychosis service units were contacted via management and agreed to participate. Seven units were included, with one excluded because it aimed to treat only elderly people. Inclusion criteria were being admitted to a psychiatric outpatient clinic specializing in psychosis and being a parent of at least one minor child. An unknown number of parents who were considered unable to participate in research by their care provider due to intellectual or psychiatric problems were not invited to participate.

Adult patients who had participated in one of the childfocused interventions received verbal and written information about the research project via care providers and were later given further information by the research staff. If the parent agreed to participate, a meeting was scheduled at a place preferred by the parent. Data collection took 2 to $3 \mathrm{~h}$ and included a questionnaire and a qualitative interview. 
Each participant was given a 10-euro voucher for participating. The study was approved by the Regional Ethics Review Board, University of Gothenburg (ref. nr. 599-15).

\section{Measures}

The interview guide was semi-structured and included questions on parenting and on parents' perceptions of their child, and experiences of participating in family interventions. For this particular study, questions related to the intervention were excluded.

The interview questions aimed to gain an understanding of the informant's perceptions of family life, their parenting, how their parenting was affected by their illness, and to get an image of how they perceived their child, and their child's wellbeing and social situation. Examples of interview questions are; "Could you describe an ordinary day in your family?", "How do you handle conflicts with your child?", "How do you think your psychosis affects you as a parent?", and "How would you describe your child?" All questions were open-ended, and follow-up questions were used to gain a deeper understanding of the participants' experiences and perceptions and to clarify potential misunderstandings. The interviews lasted from $45 \mathrm{~min}$ to $1.5 \mathrm{~h}$.

Because parenting can be difficult to discuss with people whose parenting ability might be questioned, the interviews were conducted in an informal style and the interviewer occasionally talked about own experiences of being a parent. For some, this approach seemed to have a calming effect and they became more talkative.

\section{Data Analysis}

Data was analyzed according to Braun and Clarke's thematic analysis (2006). After an initial reading of the interview transcripts, all data related to the research aim were analyzed deductively using Grusec and Davidov's (2010) model of parenting. The data within each domain were coded inductively to form the subthemes. During thematic analysis, the authors approached the data from a critical realist perspective, applying a semantic, low-level interpretation.

First, all meanings units in which parents themselves made a link between their illness and their parenting were selected for analysis. The aim was not to give an overall view of parenting, but to focus specifically on links between illness and parenting. However, if participants spoke about being on sick leave because of their psychosis and discussed how this affected their presence as parents, the meaning unit was marked. The authors then discussed and explored the essence of the five theoretical domains of protection, reciprocity, control, guided learning, and group participation that constitute Grusec and Davidov's (2010) model of parenting. The essence of each domain was summarized, and concepts that were significant were noted as codes. During the third step, the first author categorized all relevant data deductively using these codes. Fourth, the second author read through all meaning units to make sure they were placed in the most suitable domain. When disagreements arose about the fit of a quotation, the quotations were discussed and recoded when appropriate. Details of how each participant contributed to each domain are presented in the supplementary online material. During the fifth step of the analysis, the first author recoded the meaning units in each domain inductively (on a semantic level). In the sixth step, the semantic codes were conceptualized at a higher level of interpretation. All authors discussed and reorganized the inductive codes and quotations into subthemes within each domain.

\section{Reflexivity and Ethics}

It is acknowledged that the background and standpoint of the researcher will interact with the research process and influence the conclusions drawn (Elliott et al. 1999). One solution applied to avoid preconceptions about how psychosis affects parenting was parallel coding, an efficient means of ensuring rigor in the analysis (Yardley 2000). An equally important aspect of doing research on sensitive issues is ethics (Yardley 2000). Besides following ethical guidelines, we applied ethical considerations to every step of the study. For example, the parent's well-being was always a higher priority than the research question. Likewise, a child's well-being was always a higher priority than their parent's; when there was concern for a child, the patient's care provider was informed and, when necessary, social services were alerted.

\section{Results}

Each main-theme commences with a brief description of the theoretical domain (Grusec and Davidov 2010), followed by a summary of the inductively generated sub-themes. The main theme contains data-based sub-themes. Themes are numbered to facilitate reading of the text and the table. Pseudonyms were used to refer to specific participants.

\section{Protection}

The domain of protection includes the parent's ability to provide security, reduce or alleviate child distress, and protect the child against harm (Grusek and Davidov 2010). The sub-themes related to the domain of protection concern parents' descriptions of their failures to protect and comfort their child because their illness of psychosis hindered those 
abilities. Some parents also perceived themselves as a threat to their child's safety. Another aspect that emerged was children's persistent or increased distress in response to the parent's own anxiety. There were also descriptions of children providing emotional support to parents experiencing anxiety or distress.

\section{In need of vicarious protectors}

The parents expressed that their will to protect and comfort the child was hindered by their illness of psychosis. Hindrances could be practical (e.g., hospitalizations) or emotional (fatigue, depression, or hearing voices). The parents emphasized the importance of professionals, friends, or relatives standing in as vicarious protectors for the child during such phases, "If you don't dare to trust yourself, you need someone who is your support control". (Fatima) For some, vicarious protectors was particularly important when the child's own wellbeing was affected. Monica, whose 12year-old son had expressed suicidal thoughts, had asked her psychologist for support: "I felt that I could not handle his problems along with all my own problems."

To protect the child often meant setting one's own needs aside and allowing others to take responsibility. This was a painful process that required insight into one's limitations as a parent. For John, prioritizing his daughter's needs meant accepting that he could not take care of her and that she was better off in a foster family.

I have accepted that she can't be with me because I know my daughter is fine now, but it was hard in the beginning, that I wasn't allowed to see her. Now I see her and talk to her and I can see that she's fine. (John)

Some parents expressed disappointment that health care staff and social services had not protected their child well enough, but had rather focused on the parent's needs, "I wish someone had protected him. I mean I was ill for 2 years before someone asked about my children." (Kathy)

\section{Protecting children from oneself}

Another recurring theme in the protection domain was avoidance and withdrawal as strategies to protect the child from becoming distressed or worried by their parent's illness. Avoidant strategies were used primarily with illnessrelated topics when parents tried not to talk about or name their illness. Withdrawal was used during psychotic episodes, for example, by retiring to another room or by staying away from home. "When I was psychotic, I stayed away for long periods. I didn't want her to see me in such bad shape." (John) Other parents described how, despite severe symptoms, they realized that they should not share their delusions or hallucinations with their child.

I knew that when I heard voices that told me that something horrible was going to happen to them or that they [the children] had been sexually abused, I knew that wasn't true, so I protected them from it. I kept quiet or stayed away. (Kathy)

Despite the strategies of withdrawal and avoidance, some parents were afraid of losing control over their anxiety and delusions and being unable to protect their child from themselves. Annica feared losing control over her selfharming behavior and cutting herself in the presence of her son. Veronica feared that she would lose control and become verbally abusive to her son.

A few parents described more extreme examples of how voices were a risk to the child's safety. Fatima, whose 8year-old son lived with his father because of her severe psychotic symptoms and anxiety, described that powerful voices and delusions made her think about killing her son.

I have had compulsions that I want to kill him. I haven't had those thoughts recently now, but I'm afraid they'll come, so I think "I hope I do not think so now" and then it gets strange to be with him. (Fatima)

\section{The child's needs for comfort causes distress}

Parents described times when the child's need for comfort caused them anxiety and distress. Even minor things like the child catching a cold or grazing a knee could cause parental anxiety. Some parents attributed some of their distress to their own difficulties in separating their own distress from their child's anxiety.

It's difficult when my son gets anxious, I think. It's hard not to go in and mix it up with myself, to project my feelings on him. [It's hard] to see him as an individual, because he is his own person. (Kathy)

Others attributed their difficulties in providing comfort to their own mood disorders or distracting voices "Maybe my voices were angry and I shouted, 'No I don't want to talk now!'” (John). Evelina's son's rejection of her attempts to comfort him was painful:

I'm not even allowed to hug him; he hardly ever hugs me. He thinks I'm very tense, and then he doesn't let me get near him; he feels that I'm tense. But I wish I was allowed to get closer to him. 


\section{The child as protector}

In general, the parents described their children as considerate, caring, and emotionally supportive "He notices right away if I'm tired and always asks, 'How are you, mum, are you tired?"' (Monica). There were also descriptions of children who took responsibility for reminding the parent about medications, mainly in an effort to prevent the parent's hospitalization or increased anxiety. Although the parents talked about their children's empathy in positive terms, some expressed feeling guilty for the child's preoccupation with their well-being. Furthermore, some parents worried about their children protecting them as parents by keeping their worries and problems within themselves. In such situations, the other parent or a care provider could have an important role.

I think he carries many hard things within himself that he doesn't talk to me about. He talks to my care provider about it, and he doesn't say it to me. He doesn't want to hurt me, he wants to protect me and not make me sad. (Monica)

\section{Reciprocity}

The domain of reciprocity refers to parent-child exchanges in which the parent has to reciprocate or comply to a reasonable extent with the child's demands for attention and cooperation as in shared play (Grusec and Davidov 2010). These parents described their reciprocal interactions with their children as obstructed by distracting voices, delusions, depression, or fatigue. As reciprocity also involves the child, one sub-theme concerns descriptions of the children's responses to their parents' symptoms.

\section{In a world of my own}

The parents' major difficulties in interactions with their children were staying focused and taking part in mutual activities such as communication and play. These difficulties arose partly from depression and tiredness, partly from delusions and hallucinations. Annica speculated about how her withdrawal affected her son: "Sometimes I'm not present. I go into my own little world, and that affects my behavior and presence." Evelina described her son's dissatisfaction with her difficulty in listening: "He says, 'You never listen, Mum.' He thinks I'm not interested but my head is full of voices."

Although most parents were aware of their withdrawal, a few were uncertain whether or not it affected their child "I was lost, but I don't know if they noticed, because I couldn't talk about it, because the voices didn't allow me"
(Sean). However, many expressed feelings of inadequacy or guilt over their inability to interact with the child at times.

\section{Lack of energy}

Fatigue and lack of energy were common hindrances to reciprocity and mutual interaction. For some parents, the tiredness followed a psychotic episode; for others it was related to depression and anxiety. "When I'm ill I stay in bed and the children notice that I'm ill then" (Grace). Isac described tiredness and lack of energy as a result of the mental health and overweight side effects of neuroleptic drugs.

Some parents talked about anxiety as particularly affecting their capacity to interact with their child. Annica said that her anxiety made her want to "shut everyone out. I don't want anyone to be close to me then." For John, tiredness and anxiety made him feel that he had lost parts of his daughters' childhood since he had left her mother, who was also mentally ill, with all responsibility.

\section{The child's response to symptoms}

Some parents described the child's reactions when the parent's illness affected parent-child interactions such as play. Children most commonly became either frustrated and attention-seeking or calm and less demanding. Although many parents described being aware of the child's wishes for interaction and play, they had difficulties meeting these needs. In response, some children became worried, frustrated, and attention-seeking. "He acts out more; he wants attention, and it's like everything he does gets amplified." (Evelina)

Andy, the single father of a 14-year-old daughter, said that she called his medication "angry-pills," and that she became frustrated when he was taking them. While other parents also described their children reacting with frustration and anger, particularly when the parent's responses to voices disturbed parent-child interactions, some children were described as adapting and becoming calmer when the parent was ill, seeking interaction by suggesting less demanding activities.

He is more like this, "Can we paint a little?" So he adjusts, he becomes more responsive despite being so young. He understands that I'm tired and I want to play in calm way, like watching a film together. (Annica)

\section{Control}

The domain of control involves situations in which the parent must demonstrate an appropriate level of power and authority to modify or stop the child's behavior so the child 
can acquire certain social skills and meet societal expectations (Grusec and Davidov 2010). The interviews contained few descriptions of non-compliant children or interactions that required authoritative parenting and no examples of parental strategies or resources used to modify socially unacceptable behavior. Instead, parents described their own lack of control, how lack of energy led to that lack of control, and how fear of negative reactions could make some of them avoid rules and limits.

\section{Lack of energy leads to lack of control}

Just as lack of energy affected the parents' capacity for reciprocal interaction, it also affected their capacity to set limits and handle conflicts constructively. The main theme was that because of anxiety, depression, or fatigue, the parent avoided structure, routines, and setting limits for the child, mainly to avoid disputes that required more energy than letting the child have its own way. There were also descriptions of how the parent's lack of energy influenced the child to become more outgoing and demanding, which in turn resulted in conflicts that the parent could not handle constructively.

In periods when I feel good, it does not affect me, but during those periods when I'm extra weak and have more anxiety, it affects me because I do not have-I do not have the same energy. I do not have the same stamina. It's hard to be with him, and it's often then the big conflicts come and everything gets much more difficult. (Annica)

In various ways, some parents' lack of control required support, whether from the other parent, from adult- or child psychiatry, or from social services. For example, Henny had received help from social services and described how her son's behavior had improved as she learned how to be more authoritative. A few parents described how their children took advantage of their parent's lack of energy to get their own way: "He knows when I don't have the energy to discuss [something]. He thinks, 'If I ask Mum if I can take a sweet, she will say yes." (Kathy)

\section{Fear of emotional reactions}

For some parents, lack of control and inability to set limits was caused by a fear of conflict. Some were afraid of upsetting their child since the child's dissatisfaction could provoke anger in the parent and in turn make the parent ill. For others, control, limits, and anger were reminders of traumatic experiences in their family of origin. Veronica described how her childhood, marked by sexual and physical abuse, had made her afraid of repeating the behaviors of her physically abusive father. Fatima described a similar background and fear of upsetting her son.

I get reminded of when I was a little, and I don't want him to experience the same, but he's sad because of things other than [those] I might be sorry for. He gets sad when we play games and he loses, and that's nothing I need to get anxious about, but I'll get anxious anyway, so I let him get what he wants.

Other parents identification with their child's anxiety about going to school or participating in social activities made them hesitate to use parental discipline. For example, Kathy said: "I want him to go [to school], but I'm afraid that I'm not persistent enough, because I know what it's like to have anxiety".

\section{Guided Learning}

The domain of guided learning concerns situations in which the parent needs to help the child to master specific skills and to support the child's learning and competence through parental organization, communication, planning, and appropriate response (Grusec and Davidov 2010). These parents' thoughts about guided learning mainly concerned whether and how they should teach their child about their illness, symptoms, and medications. Another theme was the parents' needs for support in providing guided learning. They described needing help with both structure and emotional responsiveness, especially before and after a psychotic episode.

\section{To teach about parental illness}

Much of the parents' perceptions about guided learning became apparent when they described their thoughts about their illness. A major topic for many was whether, how, and when they should explain their illness to their child. The parents' approaches varied: most avoided the subject, while others struggled to find a level of explanation appropriate to the child's age. Some seemed more intrusive in their need to explain the symptoms of their illness.

Many of the parents reported avoiding the topic of illness, often because of a fear of upsetting or worrying the child, "Generally, I don't like to talk and ruin things for her, so I've taken it very easy." (Andy) Although some children had witnessed acute hospitalizations, the parents had not talked about what had happened nor how the child had experienced these situations. Neither had Sean, who replied that he was unsure of what information the children had received after his suicide attempt. 
I think the wife said that I had back pain, but the big one knew about it because I had written a suicide note /.../ We have not talked so much about it really, it has not been so, no, she never asked.

There were also parents who struggled to find an ageappropriate explanation. "I thought, that's something we should keep alive as she develops - how to talk to her about it." (Isac) Other parents seemed more intrusive in their need to provide the child with information about their illness, and some described several situations when they had talked to the child about their symptoms and diseaserelated behaviors despite the child's uninterest. Fatima talked about a letter she sent to her son when he was 8 years old.

I wrote a letter to him in which I explained about my illness and I wrote "When you were little, I thought Dad was hitting you and that he sexually abused you," and that I hear voices and see visions that no one else sees or hears, and he just said, "That's what I thought." (Fatima)

\section{Guidance requires guiding}

Some parents said that helping the child with cognitive, social, and emotional tasks required support from others. Most commonly, "others" were professionals in psychiatry or support provided by social services. For example, Isac, whose wife had postpartum depression following their daughter's birth, had been helped by a children's coach, who taught him how to meet his child's emotional needs adequately. Other parents had been helped by professionals such as therapists or case managers. Evelina had received support for her tendency to over-involve her son in her concerns.

I think about what my therapist said to me, because I should not overdo and talk too much about my problems with my son, about all my concerns with my son. Sometimes it has been like that, that I talked too much to him and he has been invisible.

Parents also described that their need for support varied according to phases of their illness. Furthermore, a few parents expressed that their guiding ability had developed along with their child's development, and that the child had taught them how to be parents, "I might need to talk about parenting, but the child teaches the parent to be a good parent." (Andy)

\section{Group Participation}

The domain of group participation involves situations in which the parent provides the child with opportunities to observe and experience interaction with others to become and enjoy being part of social groups. The child observes the parent as well as the routines and habits in the family, which represents their membership in a social group (Grusec and Davidov 2010). A consistent theme in the group participation domain was that these parents' illness guided and/or obstructed the child's social identity and grouprelated socialization. Parents also described ambivalence toward themselves as role models for their children.

\section{Ambivalence toward oneself as a role model}

The parents perceived themselves as models for their children. Their satisfaction with what their children learned by growing up with an ill parent as a role model varied. Some emphasized their children's learned empathy, their ability not to take health and well-being for granted, and their knowledge about periods in life when it is necessary to accept and value help from others. Other mentioned that the children learned to value intrinsic and social goods over material things because of their family's financial problems. Isac was clear that he and his wife, who had recurring depressions, acted as positive role models in a difficult social climate in which people are easily perceived as weak.

It's not negative to be weak or to be a human in need, and I think [the child] values that. It may be something she gets from us, what's important in life. We have a social image that can be tough, but a reality that is different because people are fragile and break, both in life and in marriage. Relationships can break in different ways, and I think that she gets an empathetic ability from us because we're both ill.

However, the same parents who described positive consequences of their illness on them as models also described negative consequences. Their concerns were mainly related to how their lack of energy, tiredness, and need to sleep several times during the day affected their children. Thus, there was ambivalence toward the effect of the illness on the child's chances to participate in cultural practices by observing them as models.

I don't do much so in that way I'm not a good role model. I have no psychotic symptoms, but after a psychosis you go down into depression and melancholy, and I'm afraid that affects her negatively. (Isac) 
Isac and several other parents attributed lethargy to both symptoms following a psychotic episode and the side effects of neuroleptics. Other aspects of the illness's effect on parents as role models were being on sick leave, which could make the child feel ashamed, and worry that children would be socialized into cultural exclusion because of their parents spiritual and religious beliefs, "I wish I had not told them that, I do not want them to tell their friends that I believe in angels." (Kathy)

\section{Financial problems as an obstacle for promoting the child's group membership}

One of the most prominent obstacles to the parents' ability to promote the child's group participation was financial difficulties. All parents reported that their poor financial situation because of living on sickness benefits affected the child, especially in the sense that the child could not have the same material standard of living as other children in the same age. Maintaining the same standards as their friends, and especially having similar clothes, was described as particularly important for older children.

I would like to buy things for my children, but I can't buy anything for them. Other children laugh at their clothes; that's the help I would like. Can you help me with that, with a new washing machine? (Grace)

The parent's financial problems also prevented the child from engaging in leisure activities or social activities such as going to the cinema. Other participants described this lack in more general terms.

I'd like her to see more of the world. It can get a bit smothering here in the coziness. But it's the economy. To see the world and such things. But I have sickness benefits and some liabilities, so we live on subsistence, but it works. (Andy)

\section{Parental illness sets the agenda for routines}

Several of the parents described their difficulty maintaining routines because of their illness. Some described how mealtime routines were obstructed by their tiredness or anxiety; others said that the child's day care schedule had to be adjusted to the parent's well-being; and harmful voices hindered some of them from taking the child to activities or going shopping. There were also parents who emphasized how important it was to have flexible and practical support when they could not maintain the child's daily routines.
It's not easy when you have this illness that I have. When it comes, you really need to get all the help you can get. Eh, for the sake of the children. It may be important that you know that sometimes the structure around us fails. (Monica)

For some, the retention of routines appeared to be synonymous with good parenting. A few parents said that they had learned the importance of routines from care providers or family interventions and their approach appeared to be instrumental.

I go to bed and sleep and on an ordinary day I get up and do things that I have to do before the children come home. They don't eat breakfast at home, they eat at school, and when I get up in the morning I'm tired because I'm ill, and sometimes I shower the little one. I'm a mum, I cook for them. (Sonia)

\section{Group belonging through the parent's illness}

Generally, the parents described an isolated family system lacking regular contact with relatives and friends. The child's social network was also limited, partly because of the family's financial situation, but also because the parent's illness prevented the child from taking friends home after school; only a few parents mentioned that their child had leisure activities. Many parents were aware of the negative consequences of this isolation, but expressed few ideas of how to change it. What emerged, however, was that when structured activities for child were described, they revolved around the child's role as a relative of a mentally ill parent. "He has been in group for children with divorced parents and in a group for children with parents who are mentally ill, so there have been many groups for him lately." (Monica)

Sophia described how her children had taken part in two different family interventions. The first one related to her initial diagnosis of bipolar disorder, and the second to her new diagnosis of schizoaffective syndrome. One of her children had also been to summer camp for children of parents with bipolar disorder.

They have had support. This was a fun experience: we went on a free camp with [name of organization] when I was diagnosed as bipolar. You've heard about that? My daughter thinks it developed her personality /.../ but most children didn't live with the ill parent so they felt a bit special. (Sophia) 


\section{Unpredictable Absences}

The final theme concerns all aspects of parenting, and can therefore not be placed under a specific domain. The theme concerns parents' mental or physical disconnection or absence from the child during periods of psychotic episodes. For a few parents, psychosis around the time of childbirth had devastating consequences as they lost either custody or contact with their child. "I had a psychosis. I was hospitalized for 300 days during her first year. She has lived with her dad since then; it's been 13 years now." (Annica). Although the consequences were not equally devastating for everyone, all parents described how their illness, to various degrees and in different ways, had interrupted the parent-child relationship. I came in and thought 'Who is he, why are there toys here?' That's scary, to lose one's child for such a long time, that's the worst part to me. (Veroncia)

\section{Discussion}

The present study aimed to explore how parents with psychosis experience that their illness affects parenting. All domains in Grusec's and Davidov's model of parenting (2010) were described as negatively affected by symptoms. Periods of depression, lack of energy, and fatigue hindered many of the parents to create and maintain family routines. Furthermore, hallucinations and delusions seemed to affect aspects of parenting such as providing protection and support and taking part in reciprocal interaction. To compensate for some of these insufficiencies, parents described withdrawing from the child and/or seeking support from their social and professional networks to protect and meet the needs of their children.

In the domain of protection, appropriate parenting involves responding to distress in a way that the child perceives as comforting and helpful (Grusec and Davidov 2010). According to our findings, depression and distracting voices obstructed the parents' capacity to protect and comfort their children. Some parents also expressed that their children's need for comfort made them distressed and anxious. These results are consistent with previous studies indicating that symptoms such as delusions, hallucinations, depression, and fatigue affect parents' attention and ability to meet the child's emotional needs (Healy et al. 2016; Kahl and Jungbauer 2014).

Grusec and Davidov (2010) also stress that unneeded protection and comfort are inappropriate responses (Grusec and Davidov 2010). Our findings suggests that some parents, because of hearing voices or paranoia, protect their children from their own purely internal threats. For children, such seemingly unmotivated protective behaviors can be unpredictable, confusing, and restrictive of their necessary explorations. Although some parents, in periods of severe symptoms, withdrew from their parental role in order to protect the children, it is likely that the child was left alone to cope and understand what was happening.

An important outcome of appropriate parental protection is that children develop a greater ability to manage stress and to self-regulate distress (Grusec and Davidov 2010). There is robust evidence that children of parents with schizophrenia are at heightened risk of attention deficit hyperactivity disorder (ADHD) (Sanchez-Gistau et al. 2015), a disorder characterized by deficits in self-regulation. These parents' descriptions of unpredictable comfort and difficulties in regulating the child's distress may be important to consider in exploring the association between parental psychosis and ADHD in children.

In the domain of reciprocity, parenting involves accommodating the child's reasonable requests of for interaction (Grusec and Davidov 2010). In this study, fatigue following a psychotic episode or medical treatment, as well as difficulties in staying focused because of voices, interfered with parents' capacities to communicate and play with the child. According to a review of mother-infant interaction in parents with schizophrenia, there is a lack of studies exploring interaction beyond 36 months (Davidsen et al. 2015). However, three studies showed that mothers with schizophrenia, compared to mothers with affective disorders, had less mutually satisfying, engaged, and smooth interaction at 4 months (ibid). Studies exploring parent-child interaction from the child's perspective showed that children experience their parent with psychosis as mentally absent, emotionally unavailable, and as more focused on their own personal problems and symptoms than on the interaction with their child (Duncan and Browning 2009; O'Connell 2008). Our findings indicate, unsurprisingly, that hearing voices has negative effects on parents' ability to focus when interacting with their child. However, the fact that some parents related the difficulties to side-effects of medication may be important for health care staff to notice. Furthermore, how medical treatment with for example neuroleptics affects parenting abilities is a blind spot in research, and requires further exploration considering the amount of patients who receive medical treatment and have minor aged children. Another important finding was that the children were described as reacting with anger and frustration or becoming calm and withdrawn. A focus in future studies could be to explore the relationship between externalizing and internalizing behavioral problems (Donatelli et al. 2010) and parents' capacity to comply with their children's wishes for mutual interaction.

Appropriate caregiving in the control domain involves applying an appropriate amount of authority in order modify the child's behavior (Grusec and Davidov 2010). In 
general, control and discipline was an absent topic in the interviews and the parents attributed their lack of control to their lack of energy. Some parents also expressed being afraid of upsetting the child, dreading both the child's and their own emotional reactions. There is a dearth of studies investigating parental discipline or control in this specific sample. However, parental self-efficacy, warmth, and positive discipline practices have been found inversely related to depressive symptoms (Jones and Prinz 2005). Explanations of these results seem to be in line with what the parents in the present study described; that avoiding disputes by letting the child have its' own way, requires less energy than setting limits.

Effective parenting in the guided learning domain involves suitable structure, information, strategies, and feedback that children need to learn and improve important cognitive, emotional, and social skills (Grusec and Davidov 2010). The major issue in these interviews was the parents' concern about how to talk to and inform their children about their mental illness. The prominence of this theme may have been related to the parents' previous participation in interventions aimed to facilitate communication about parental illness. The results, however, indicate that despite participating in these interventions, parents' provided their children either unrestrained or insufficient guidance on how to comprehend and cope with their parent's illness. Another important finding was that parents expressed a wish for support in their parenting role to enable them to facilitate their child's development. Sensitive scaffolding in the area of guided learning requires awareness of the child's developmental stages and an ability to take the child's perspective (Grusec and Davidov 2010). Difficulties in taking the child's perspective may relate to a preoccupation with one's own problems; leaving less energy to focus on the child's emotional needs. The scarcity of examples concerning guided learning could also be related to the results in the domain "Group participation", that mental illness, unemployment, and limited social networks restricts the parent's capacity to support the child's abilities in a domain focusing on cognitive and social scaffolding. Furthermore, guidance in this domain requires parents to be goal oriented, structured, and strategic (Grusec and Davidov 2010), abilities that may be undermined by low socioeconomic status and mental health problems.

In the domain of group participation, parents are seen as models for how things are done in wider social contexts and groups (Grusec and Davidov 2010). The most prominent obstacle to the parents' promotion of their child's participation in in-groups was financial difficulty, which hindered the children from having the same material standards as their peers. Financial difficulties as an obstacle for parental functioning and child well-being is a problem that appears in studies from both parents' and children's perspective (Dolman et al. 2013; Kahl and Jungbauer 2014). Being unable to dress as other youths do and having an identity influenced by the parent's mental illness could place the child's chances of joining an in-group on shaky ground. Parents' ambivalence toward themselves as role models, along with their descriptions of exposing their children to periods of odd beliefs and behaviors, could also explain unusual social and behavioral expressions in children of parents with psychosis.

Finally, the new/additional theme of "Unpredictable absences" crosses all domains in Grusec and Davidov's model (2010) as parental psychosis involves mental and/or physical absence from the child. Mental withdrawal due to psychoses, and longer periods of hospitalization pose a constant threat to the fundamentally important continuity in the relationship between parent and child. This theme may be important to consider when examining the heightened risk for children of mentally ill parents to be insecurely attached (e.g., Davidsen et al. 2015).

\section{Limitations}

The major limitation of this study is that the interview guide was not explicitly structured according to the model of Grusec and Davidov's (2010). However, all domains of the model were covered during the interview by direct or indirect questions, such as those about parent-child interactions on an ordinary day. Another weakness was that the inclusion criteria may have affected the sample and consequently the results as parents included in family interventions generally tend to function better than non-participating parents (Strand and Rudolfsson 2017). Moreover, all participants had completed one of the two interventions, that both aim to open up family communication about parental mental illness and increase awareness of how children are affected by parental mental illness. Both weaknesses related to the inclusion criteria may have contributed to an overrepresentation of well-functioning parents. On the other hand, the parents in the present study did describe numerous parenting difficulties and therefore contradict findings from Campbell et al. (2018), who suggested that parents with psychosis generally provide adequate parenting. We believe that these discrepancies between results are not as much related to differences in inclusion criteria as they are to differences in data collection methods. Sensitive issues such as parenting may benefit from exploration through in-depth interviews allowing the participant to reflect on sensitive and complex issues.

Acknowledgements This research was funded by Swedish Research Council for Health, Working life and Welfare. Open access funding provided by University of Gothenburg. 
Author Contributions JS: designed and executed the study, collaborated in analyzing data, and writing and editing of the final manuscript. PB: collaborated in analyzing data, and writing and editing of the final manuscript. KG: collaborated with the design, analysis, writing and editing of the final manuscript.

\section{Compliance with Ethical Standards}

Conflict of Interest The authors declare that they have no conflict of interest.

Ethical Approval The study was approved by the Regional Ethics Review Board, University of Gothenburg (ref. nr. 599-15).

Informed Consent Informed consent was obtained from all participants included in the study.

Publisher's note Springer Nature remains neutral with regard to jurisdictional claims in published maps and institutional affiliations.

Open Access This article is distributed under the terms of the Creative Commons Attribution 4.0 International License (http://crea tivecommons.org/licenses/by/4.0/), which permits unrestricted use, distribution, and reproduction in any medium, provided you give appropriate credit to the original author(s) and the source, provide a link to the Creative Commons license, and indicate if changes were made.

\section{References}

Beardslee, W. R., Gladstone, T. R., Wright, E. J., \& Cooper, A. B. (2003). A family-based approach to the prevention of depressive symptoms in children at risk: evidence of parental and child change. Pediatrics, 112, 119-131.

Belsky, J. (1984). The determinants of parenting-a process model. Child Development, 55, 83-96.

Blegen, N. E., Hummelvoll, J. K., \& Severinsson, E. (2010). Mothers with mental health problems: a systematic review. Nursing \& Health Sciences, 12, 519-528.

Blegen, N. E., Hummelvoll, J. K., \& Severinsson, E. (2012). Experiences of motherhood when suffering from mental illness: a hermeneutic study. International Journal of Mental Health Nursing, 21, 419-427.

Bornstein, M. H., Tamis-LeMonda, C. S., Hahn, C. S., \& Haynes, O. M. (2008). Maternal responsiveness to young children at three ages: longitudinal analysis of a multidimensional, modular, and specific parenting construct. Developmental Psychology, 44, 867-874.

Braun, V., \& Clarke, V. (2006). Using thematic analysis in psychology. Qualitative Research in Psychology, 3, 77-101.

Campbell, L., Hanlon, M. C., Poon, A. W. C., Paolini, S., Stone, M., Galletly, C., \& Cohen, M. (2012). The experiences of Australian parents with psychosis: the second Australian national survey of psychosis. Australian and New Zealand Journal of Psychiatry, 46, 890-900.

Campbell, L. E., Hanlon, M. C., Galletly, C. A., Harvey, C., Stain, H., Cohen, M., \& Brown, S. (2018). Severity of illness and adaptive functioning predict quality of care of children among parents with psychosis: a confirmatory factor analysis. Australian and New Zealand Journal of Psychiatry, 52, 435-445.

Davidsen, K. A., Harder, S., MacBeth, A., Lundy, J. M., \& Gumley, A. (2015). Mother-infant interaction in schizophrenia: transmitting risk or resilience? A systematic review of the literature. Social Psychiatry and Psychiatric Epidemiology, 50, $1785-1798$

Diaz-Caneja, A., \& Johnson, S. (2004). The views and experiences of severely mentally ill mothers-a qualitative study. Social Psychiatry and Psychiatric Epidemiology, 39, 472-482.

Dolman, C., Jones, I., \& Howard, L. M. (2013). Pre-conception to parenting: a systematic review and meta-synthesis of the qualitative literature on motherhood for women with severe mental illness. Archives of women's mental health, 16(3), 173-196.

Donatelli, J. A. L., Seidman, L. J., Goldstein, J. M., Tsuang, M. T., \& Buka, S. L. (2010). Children of parents with affective and nonaffective psychoses: a longitudinal study of behavior problems. American Journal of Psychiatry, 167, 1331-1338.

Duncan, G., \& Browning, J. (2009). Adult attachment in children raised by parents with schizophrenia. Journal of Adult Development, 16(2), 76-86.

Elliott, R., Fischer, C. T., \& Rennie, D. L. (1999). Evolving guidelines for publication of qualitative research studies in psychology and related fields. British Journal of Clinical Psychology, 38, 215-229.

Engur, B. (2017). Parents with psychosis: Impact on parenting and parent-child relationship. a systematic review. Global Journal of Addiction and Rehabilitation Medicine, 1, 1-5.

Evenson, E., Rhodes, J., Feigenbaum, J., \& Solly, A. (2008). The experiences of fathers with psychosis. Journal of Mental Health, 17, 629-642.

Grusec, J. E., \& Davidov, M. (2010). Integrating different perspectives on socialization theory and research: a domain-specific approach. Child Development, 81, 687-709.

Healy, S. J., Lewin, J., Butler, S., Vaillancourt, K., \& Seth-Smith, F. (2016). Affect recognition and the quality of mother-infant interaction: understanding parenting difficulties in mothers with schizophrenia. Archives of Women's Mental Health, 19(1), 113-124.

Hjern, A., \& Manhica, H. (2013). Barn som anhöriga till patienter $i$ vården-hur många är de? [Children who are relatives of patients in healthcare: how many are they?]. Kalmar, Sweden: Nationellt kompetenscentrum anhöriga, Linnéuniversitetet.

Jones, T. L., \& Prinz, R. J. (2005). Potential roles of parental selfefficacy in parent and child adjustment: a review. Clinical Psychology Review, 25(3), 341-363.

Kahl, Y., \& Jungbauer, J. (2014). Challenges and coping strategies of children with parents affected by schizophrenia: results from an in-depth interview study. Child and Adolescent Social Work Journal, 31(2), 181-196.

Krumm, S., Becker, T., \& Wiegand-Grefe, S. (2013). Mental health services for parents affected by mental illness. Current Opinion in Psychiatry, 26, 362-368.

Lauritzen, C. (2014). The importance of intervening in adult mental health services when patients are parents. Journal of Hospital Administration, 3, 56-65.

LeFrancois, B. A. (2012). Distressed fathers and their children: a review of the literature. International Journal of Social Psychiatry, 58, 123-130.

Leijdesdorff, S., van Doesum, K., Popma, A., Klaassen, R., \& van Amelsvoort, T. (2017). Prevalence of psychopathology in children of parents with mental illness and/or addiction: an up-to-date narrative review. Current Opinion in Psychiatry, 30(4), 312-317.

Maybery, D., \& Reupert, A. E. (2018). The number of parents who are patients attending adult psychiatric services. Current Opinion in Psychiatry, 31, 358-362.

O'Connell, K. L. (2008). What can we learn? Adult outcomes in children of seriously mentally ill mothers. Journal of Child and Adolescent Psychiatric Nursing, 21(2), 89-104. 
Ramchandani, P., \& Psychogiou, L. (2009). Paternal psychiatric disorders and children's psychosocial development. Lancet, 374, 646-653.

Reupert, A. E., Mayberry, D. J., \& Kowalenko, N. M. (2012). Children whose parents have a mental illness: prevalence, need and treatment. MJA Open, 1(Suppl 1), 7-9.

Ripke, S., Neale, B. M., Corvin, A., Walters, J. T. R., Farh, K. H., \& Holmans, P. A., Wellcome Trust Case-Control, C. (2014). Biological insights from 108 schizophrenia-associated genetic loci. Nature, 511, 421-427.

Ruud, T., Mayberry, D., Reupert, A., Weimand, B., Foster, K., Grant, A., Skogoy, B. E., \& Ose, S. O. (2019). Adult mental health outpatients who have minor children: prevalence of parents, referrals of their children, and patient characteristics. Frontiers in Psychiatry, 10, 163-170.

Sanchez-Gistau, V., Romero, S., Moreno, D., de la Serna, E., Baeza, I., Sugranyes, G., \& Castro-Fornieles, J. (2015). Psychiatric disorders in child and adolescent offspring of patients with schizophrenia and bipolar disorder: a controlled study. Schizophrenia Research, 168, 197-203.

Smith, M. (2004). Parental mental health: disruptions to parenting and outcomes for children. Child \& Family Social Work, 9, 3-11.
Solantaus, T., \& Toikka, S. (2006). The effective family programme: preventative services for the children of mentally ill parents in Finland. International Journal of Mental Health Promotion, 8, $37-44$.

Sprong, M., Schothorst, P., Vos, E., Hox, J., \& Van Engeland, H. (2007). Theory of mind in schizophrenia: meta-analysis. The British Journal of Psychiatry, 191, 5-13.

Stein, A., Pearson, R. M., Goodman, S. H., Rapa, E., Rahman, A., McCallum, M., \& Pariante, C. M. (2014). Effects of perinatal mental disorders on the fetus and child. Lancet, 384, 1800-1819.

Strand, J., \& Rudolfsson, L. (2017). A qualitative evaluation of professionals' experiences of conducting Beardslee's family intervention in families with parental psychosis. International Journal of Mental Health Promotion, 19, 289-300.

Turiel, E. (2010). Domain specificity in social interactions, social thought, and social development. Child Development, 81, 720-726.

Wan, M. W., \& Green, J. (2009). The impact of maternal psychopathology on child-mother attachment. Archives of Women's Mental Health, 12(3), 123-134.

Yardley, L. (2000). Dilemmas in qualitative health research. Psychology and Health, 15, 215-228. 